\title{
Tidal stream transport of weakfish larvae in Delaware Bay, USA
}

\author{
P. M. Rowe*, C. E. Epifanio \\ College of Marine Studies, Hugh R. Sharp Campus, University of Delaware, Lewes, Delaware 19958, USA
}

\begin{abstract}
We conducted discrete-depth, hourly sampling for larval weakfish Cynoscion regalis at a station in southern Delaware Bay, USA, during the spawning seasons of 1988 (131 h) and 1989 (150 h). During both years, coincident measurements of current velocity, salinity, and temperature were made at 2 depths in the water column and tidal-height data were obtained from a nearby NOAA tide gauge. Results of nonparametric analysis of variance showed that larvae were significantly more abundant at depth than at the surface. Post-yolksac larvae were significantly more abundant during flood tides, but there was no effect of tidal stage on the abundance of yolksac larvae. Cross-correlation analysis indicated that post-yolksac larvae showed a periodicity in abundance around $12 \mathrm{~h}$, which is similar to the period of the semidiurnal tide in the Bay. This indicates that post-yolksac larvae may utilize selective tidal stream transport to effect retention in the estuary. Results of autocorrelation indicate that larvalpatch diameter was approximately $3 \mathrm{~km}$. Results of both cross-correlation and spectral analysis suggest that neither salinity nor sea level height serves as a cue for vertical migration. Rather, some aspect of the tidal-velocity field appears to be important.
\end{abstract}

KEY WORDS: Transport · Fish larvae - Weakfish · Retention · Estuary - Delaware Bay

\section{INTRODUCTION}

Many investigations have concluded that fish larvae can be retained in estuarine nursery areas by a process known as selective tidal stream transport (e.g. Boehlert \& Mundy 1988). Selective tidal stream transport (STST) is accomplished when larvae migrate up in the water column during flooding tidal currents and downward during ebbing tidal currents (Epifanio 1988). This allows larvae to overcome the net seaward flow of the estuary. Stimuli for these vertical migrations are not clearly understood, even though a number of triggering factors have been investigated; these include salinity (Forward 1989), pressure (Forward 1990), microturbulence (McCleave \& Kleckner 1982), and food (Fortier \& Leggett 1983).

Any study of larval dispersal demands sampling on temporal scales that are well matched to relevant physical processes. Poorly matched sampling scales

\footnotetext{
- Present address: GIROQ, Universite Laval, Ste. Foy, Quebec,
} Canada G1K 7P4 have often yielded incorrect or imprecise interpretations of transport. For example, Nelson et al. (1977) based their transport model for Atlantic menhaden Brevoortia tyrannus on monthly averages of zonal Ekman drift in the South Atlantic Bight (USA); however, Yoder (1983) showed that wind events that actually drive this flow occur at weekly, rather than monthly, frequencies (Yoder 1983). In another study, this time in the Middle Atlantic Bight, Epifanio et al. (1989) made weekly measurement of crab larval abundance off Delaware Bay and tried to infer patterns of transport from available current-meter records. However, subsequent analysis showed that weekly sampling was inadequate because larval patches were often transported completely out of the sampling area in less than a week. While the correct match of sampling scales and physical processes is particularly important in the study of STST, only a few investigations have met this criterion (e.g. Fortier \& Leggett 1983).

In this paper we present results of a study in which larvae of the weakfish Cynoscion regalis were sampled 
on a temporal scale appropriate for physical transport processes in Delaware Bay. Weakfish spawn from May through July in large estuaries along the Middle Atlantic Bight; these same estuaries serve as nursery grounds for the larvae (Mercer 1983). Thus, spawning events can be easily monitored, allowing sampling to occur during peaks in larval abundance. Weakfish spawn in the southern (= most seaward) part of Delaware Bay, and larvae are most common in that area (Goshorn \& Epifanio 1991). Larval duration is approximately 3 wk (Duffy \& Epifanio 1993), and depthaveraged, subtidal currents are seaward in the southern Bay and are of sufficient velocity to carry larvae out of the Bay before metamorphosis (Garvine 1991).

\section{METHODS AND MATERIALS}

Field sampling. We collected larvai weakfish at a station (depth $=10 \mathrm{~m}$ ) on the spawning grounds in southern Delaware Bay (Fig. 1). Weakfish spawning often occurs in 2 peaks (Goshorn \& Epifanio 1991), and

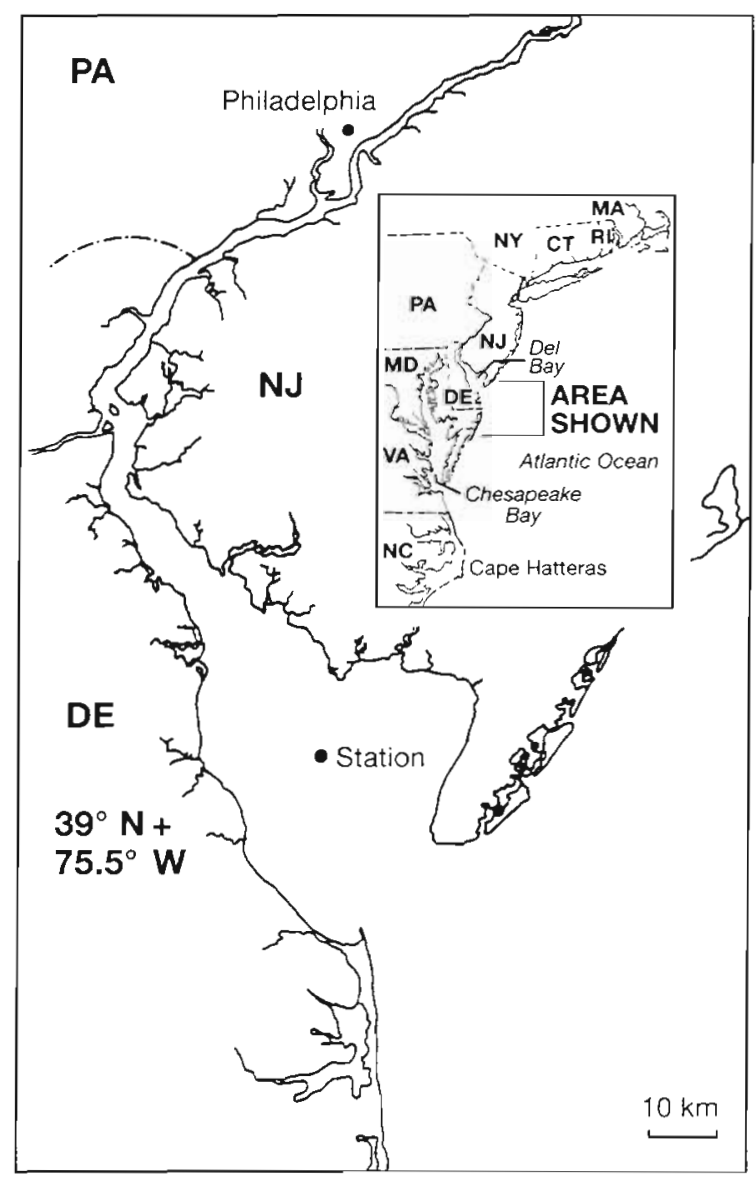

Fig. 1. Location of station on weakfish spawning grounds, Delaware Bay, USA, in 1988 and $1989\left(39^{\circ} 02.5^{\prime} \mathrm{N}, 75^{\circ} 09^{\prime} \mathrm{W}\right)$ the study included both of these periods. The station was occupied for $131 \mathrm{~h}$ in 1988 (June 17 to June 23) and for $150 \mathrm{~h}$ in 1989 (May 30 to June 5). Sampling consisted of hourly, discrete-depth tows (1,5, and $9 \mathrm{~m}$ ) from a $13 \mathrm{~m}$ vessel equipped with standard navigational and positioning devices. We used an opening/ closing, $1 \mathrm{~m}$ (diameter) plankton net fitted with $333 \mu \mathrm{m}$ nylon mesh and a TSK flow meter. Tows sampled an average of $130 \mathrm{~m}^{3}$ and $70 \mathrm{~m}^{3}$ of water in 1988 and 1989 respectively.

In each year, 2 Interocean S-4 current meters recorded current velocity, salinity, and temperature at depths of 2 and $7 \mathrm{~m}$ above the bottom respectively. Data were logged as $10 \mathrm{~min}$ averages every $15 \mathrm{~min}$ in 1988 , and as 5 min averages every $15 \mathrm{~min}$ in 1989 . Velocity components were rotated $20^{\circ}$ counter-clockwise to correspond to the NW/SE, longitudinal axis of the Bay. In 1989, we also made hourly measurements of irradiance from surface to bottom at the station (Biospherical Instruments, Model QSP-170B, Sensor QSP-200). Sea level heights at a nearby tide gauge were obtained from the NOAA National Ocean Service.

Aii samples were preserved in 5\% formaldehyde and later transferred to $70 \%$ ethanol for storage. Weakfish larvae were identified using reference specimens and keys (Lippson \& Moran 1974, Wang \& Kernehan 1979, Ditty 1989). We assigned larvae to 1 of 3 categories: (1) yolksac (visible yolksac); (2) earlystage (well-developed eyes and mouth, $<3 \mathrm{~mm}$ notochord length, NL); or (3) Iate-stage ( $>3 \mathrm{~mm} \mathrm{NL}$ ).

Analysis. Depth-averaged velocity was calculated every hour coincident with biological sampling. We defined flooding tidal currents as those with northward, longitudinal velocity; throughout this paper we refer to these currents as landward. Because data were not normally distributed and were heteroscedastic, nonparametric methods (Friedman's Random Block Test with Tukey-type nonparametric multiple comparisons and Mann-Whitney $U$-test) were used to test for significant differences ( $\alpha=0.05)$ in larval abundance with respect to depth and tidal stage (Zar 1984).

Occasional equipment failure, foul weather, and boat problems resulted in only $92 \mathrm{~h}$ of biological sampling in 1988. Plankton tows were not initiated until Hour 18 of station occupation, and 2 additional gaps of 10 and $12 \mathrm{~h}$ occurred in the plankton time series. In 1989 a $150 \mathrm{~h}$ biological time series was collected without gaps. For both years, time series of larval abundance were analyzed by autocorrelation and also by cross-correlation with relevant physical data. Analyses were conducted using software from the International Mathematical and Statistical Library (IMSL). Correlation coefficients were compared to Bartlett's standard error. Because of 2 gaps in the 1988 time series of larval abundance, a special procedure 
was used for cross-correlation with each of the physical time series. In this procedure, the complete time series (physical data) must be longer than and start before the gapped series (larval abundance). Thus only positive lags, where the complete time series leads the gapped series, could be analyzed for the 1988 data.

In a companion approach, the 1989 time series was also subjected to spectral analysis. This allows determination of the power spectrum of individual time series, as well as coherence and phase difference between 2 time series. The time series in the frequency domain were smoothed with a half-window width of 10 (equivalent to approximately 37 degrees of freedom). Although this large band-width reduces the resolution of spectral density between adjacent frequencies, the error of the spectral estimate is also decreased. A power spectrum reveals the frequency bands that contain the most energy or variance in a time series. The energies (variance) at different frequencies in the power spectrum were compared with the $95 \%$ confidence interval about a point. Coherence in the frequency domain is analogous to crosscorrelation in the time domain. Coherence is estimated relative to a level of $95 \%$ significance. The phase angle at a particular frequency represents the degree to which the 2 series are not in synchronicity.

\section{RESULTS}

Fluctuations in currents at the station were strongly semidiurnal, and the major axis of the tidal-current ellipse was oriented along the northwest-southeast axis of the Bay. Longitudinal velocities were greatest near the surface. These velocities reached $90.4 \mathrm{~cm} \mathrm{~s}^{-1}$ in 1989 (spring tides) and $69.5 \mathrm{~cm} \mathrm{~s}^{-1}$ in 1988 (neap tides) (Table 1). Depth-averaged velocities were, of course, less and never exceeded $70 \mathrm{~cm} \mathrm{~s}^{-1}$ (Fig. 2). Subtidal flow was estimated as time-averaged velocity over the study period and varied between years. In 1988 subtidal longitudinal velocity from both current meters was landward, while in 1989 the subtidal longitudinal velocity was seaward at both depths. Salinities ranged from 24.4 to $27.8 \%$ in 1988 and from 20.1 to $26.3 \%$ in 1989 . Temperatures increased throughout each study period and ranged from 20.1 to $22.9^{\circ} \mathrm{C}$ in 1988 and from 16.8 to $19.2^{\circ} \mathrm{C}$ in 1989 . The difference in mean salinity and temperature between the upper and lower current meter remained small for both years; this indicates
Table 1. Peak and mean of longitudinal component of tidal velocity from 2 current meters moored in southern Delaware Bay. Shallow meter $=7 \mathrm{~m}$ above bottom; deep meter $=2 \mathrm{~m}$ above bottom. Water depth $=10 \mathrm{~m} \mathrm{MLW}$. Values are $\mathrm{cm} \mathrm{s}^{-1}$ Peak and mean determined from hourly velocities from a $131 \mathrm{~h}$ record in late June 1988 and a $141 \mathrm{~h}$ record in late May 1989. Values in parentheses are standard errors adjusted for a decorrelation time of $3 \mathrm{~h}$

\begin{tabular}{|lrrrr|}
\hline & \multicolumn{2}{c}{1988} & \multicolumn{2}{c|}{1989} \\
& Shallow & Deep & Shallow & Deep \\
\hline Landward & 59.4 & 47.7 & 84.3 & 66.3 \\
Seaward & -69.5 & -50.1 & -90.4 & -48.3 \\
Mean & 3.1 & 3.8 & -1.9 & -0.1 \\
& $(5.7)$ & $(4.5)$ & $(7.0)$ & $(5.2)$ \\
& & & & \\
\hline
\end{tabular}
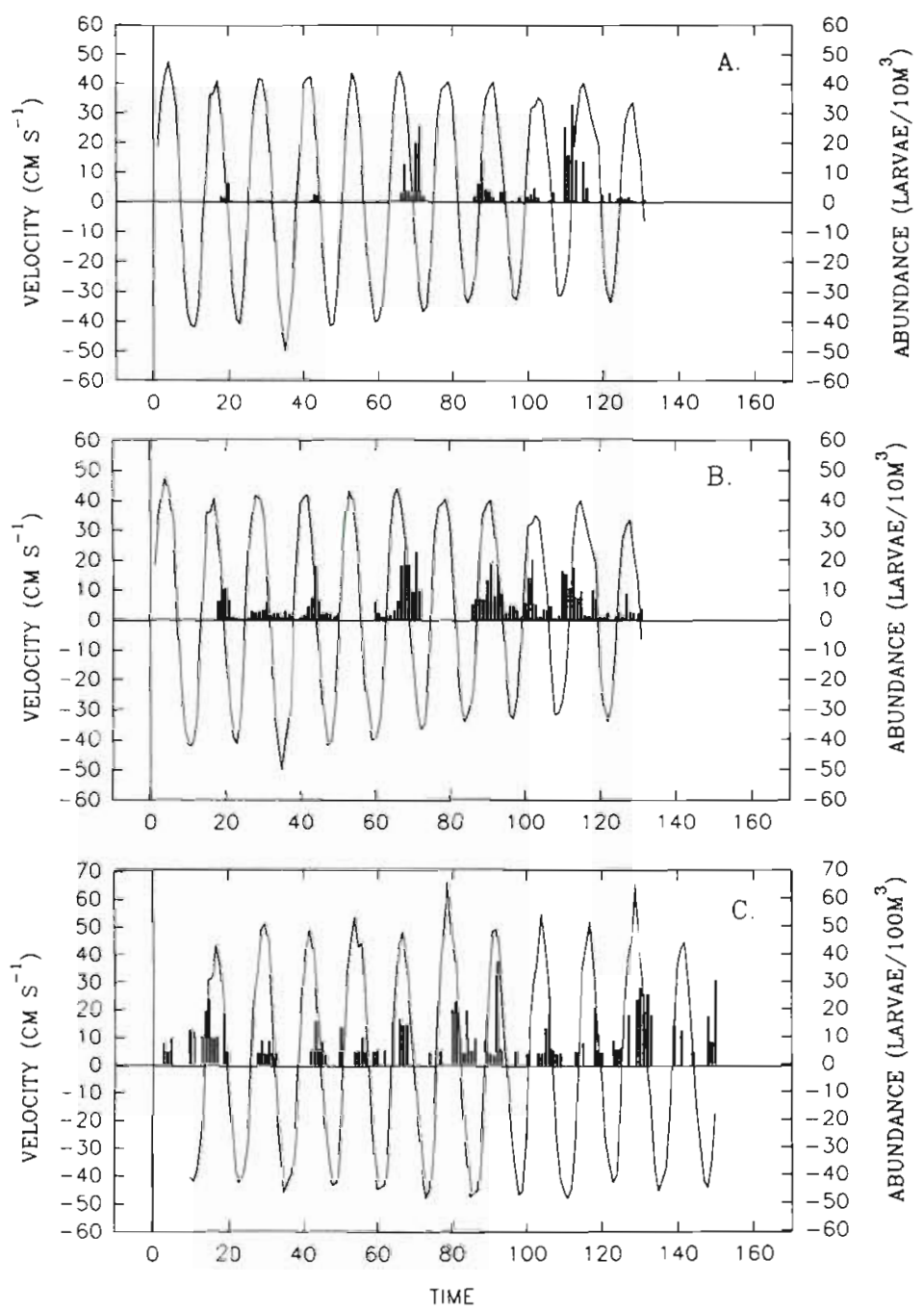

Fig. 2. Cynoscion regalis. Covariation of depth-averaged abundance of larvae with the longitudinal component of velocity in Delaware Bay. Positive values of velocity represent landward or flooding currents. Abundance represented by shaded bars. (A) Yolksac stage, 1988. (B) Post-yolksac stage, 1988. (C) All stages, 1989 
Table 2. Cynoscion regalis. Mean abundance of larvae at 3 depths in southern Delaware Bay. Abundances are larvae per $100 \mathrm{~m}^{3}$ Values in parentheses are standard errors. Differences in abundance determined by Friedman's Random Block analysis and Tukey-type unplanned multiple comparison at $\alpha=0.05$. n: no. of blocks

\begin{tabular}{|c|c|c|c|c|c|}
\hline \multirow{2}{*}{ Depth } & \multicolumn{4}{|c|}{$1988(n=45) \longrightarrow$} & \multirow{2}{*}{$\begin{array}{l}-1989(\mathrm{n}=75) \\
\text { Pooled larval abundance }\end{array}$} \\
\hline & Yolk sac & $\begin{array}{c}\text { Early stage } \\
<3 \mathrm{~mm}\end{array}$ & $\begin{array}{c}\text { Late stage } \\
>3 \mathrm{~mm}\end{array}$ & Total & \\
\hline Surface $(\mathrm{S})$ & $9.9(4.3)$ & $16.0(3.0)$ & $2.1(0.6)$ & $28.0(7.4)$ & $0.2(0.05)$ \\
\hline Mid-depth (M) & $38.6(12.6)$ & $58.7(10.9)$ & $12.5(1.9)$ & $109.9(22.1)$ & $0.8(0.1)$ \\
\hline Bottom (B) & $42.0(13.6)$ & $62.6(9.4)$ & $21.2(3.1)$ & $125.9(20.5)$ & $0.7(0.1)$ \\
\hline Tukey test & $S<M=B$ & $\mathrm{~S}<\mathrm{M}=\mathrm{B}$ & $\mathrm{S}<\mathrm{M}=\mathrm{B}$ & $S<M=B$ & $S<M=B$ \\
\hline
\end{tabular}

a well-mixed water column during both sampling periods. However, the Bay was colder and fresher in 1989 than in 1988, reflecting the earlier sampling in 1989. During the neap tides of 1988 , tidal-height amplitude ranged from 0.50 to $0.75 \mathrm{~m}$. in 1989 , spnng tides exhibited amplitudes from 0.75 to $1 \mathrm{~m}$. Maximum irradiance in the water column always occurred around midday when respective values at the surface, middepth, and bottom rcached 49.6, 3.7, and $0.8 \times$ $10^{15}$ quanta $\mathrm{cm}^{-2} \mathrm{~s}^{-1}$.

Larvae were very abundant in 1988 when total catch exceeded 30000 individuals; $32.7 \%$ of these larvae were still in the yolksac stage, $53.2 \%$ were early-stage, and $14.1 \%$ were late-stage. Less than 200 individuals were collected in 1989 , and nearly $93 \%$ were postyolksac stage. For 1988 separate analyses were conducted for each size class; for 1989, tests were run on pooled data for all larvae and results were considered relevant to post-yolksac larvae. Maximum abundance in any one sample was 847.1 larvae per $100 \mathrm{~m}^{3}$ in 1988 and 7.7 larvae per $100 \mathrm{~m}^{3}$ in 1989 . Mean abundance in the respective years was 87.9 larvae per $100 \mathrm{~m}^{3}$ and 0.6 larvae per $100 \mathrm{~m}^{3}$.

In both years larvae were significantly more abundandant in mid-depth and bottom waters than at the surface (Table 2). In 1988 there was no significant effect of tidal phase on abundance of yolksac larvae; however, surface abundance of early-stage larvae was significantly greater during flood phase than ebb phase. In addition, late-stage larvae were more abundant during flooding tides at both surface and middepth (Table 3). Results from 1989 were similar, as total abundance at surface and mid-depth was significantly greater during flood phase.

For both years, autocorrelation of depth-averaged, larval abundance revealed that decorrelation occurred at 2 to $3 \mathrm{~h}$ lag, and significant correlations did not reappear after lags of 1 full tidal period (Fig. 3). Crosscorrelation showed that maximum positive correlation between larval abundance and longitudinal velocity occurred when the time series of abundance was lagged backward in time by $1 \mathrm{~h}$. This indicates that tidal velocity led larval abundance, i.e. increases in tidal velocity were followed by increases in larval abundance. Correlations became negative at 6 to $7 \mathrm{~h}$ lag and returned to positive at 12 to $13 \mathrm{~h}$ lag (Fig. 4). This pattern was seen in correlations of velocity and larval abundance at surface and mid-depth, but not at the deepest sampling depth. Correlations with other physical factors (not shown) were simiiar except that larval abundance led sea level height by $1 \mathrm{~h}$ and salinity by $2 \mathrm{~h}$. This indicated that increases in larval abundance always occurred before comparable increases in sea level or salinity.

Table 3. Cynoscion regalis. Abundance of larvae during flood and ebb tidal phases in southern Delaware Bay. Abundances are larvae per $100 \mathrm{~m}^{3}$. Values in parentheses are standard errors. Differences in abundance determined by Mann-Whitney $U$ analysis at $\alpha=0.05$. (A) to (C) show values from late June 1988. Sample sizes for flood and ebb values are $n=23$ and $n=$ 22, respectively. (D) shows values from late May-early June 1989. Sample sizes are $n=37$ and $n=38$ for flood and ebb values, respectively. Abundances for 1989 are pooled values of all larval stages

\begin{tabular}{|c|c|c|c|}
\hline Depth & Flood $(F)$ & $\mathrm{Ebb}(\mathrm{E})$ & $\begin{array}{c}\text { Mann-Whitney } \\
U \text {-test }\end{array}$ \\
\hline \multicolumn{4}{|c|}{ A. Yolk-sac larvae } \\
\hline Surface & $12.8(7.5)$ & $7.0(4.4)$ & $F=E$ \\
\hline Mid-depth & $30.3(8.9)$ & $47.3(24.2)$ & $F=E$ \\
\hline Bottom & $50.7(23.6)$ & $33.0(13.0)$ & $F=E$ \\
\hline \multicolumn{4}{|c|}{ B. Early-stage larvae } \\
\hline Surface & $20.4(4.2)$ & $11.4(4.2)$ & $F>E$ \\
\hline Mid-depth & $70.7(16.3)$ & $46.1(14.2)$ & $F=E$ \\
\hline Bottom & $78.1(15.5)$ & $46.4(9.6)$ & $F=E$ \\
\hline \multicolumn{4}{|c|}{ C. Late-stage larvae } \\
\hline Surface & $3.4(1.1)$ & $0.7(0.4)$ & $F>E$ \\
\hline Mid-depth & $16.5(2.3)$ & $8.5(2.7)$ & $F>E$ \\
\hline Bottom & $24.2(4.7)$ & $18.2(4.1)$ & $F=E$ \\
\hline \multicolumn{4}{|c|}{ D. Pooled larval stages } \\
\hline Surface & $0.30(0.08)$ & $0.09(0.04)$ & $F>E$ \\
\hline Mid-depth & $1.26(0.24)$ & $0.31(0.09)$ & $F>E$ \\
\hline Bottom & $0.70(0.14)$ & $0.70(0.17)$ & $F=E$ \\
\hline
\end{tabular}



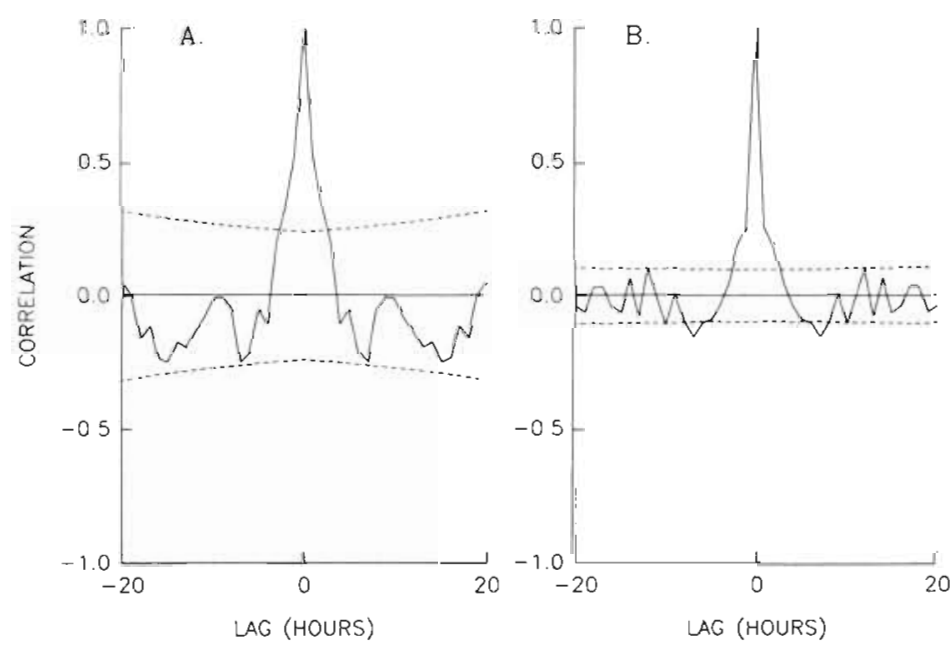

Fig. 3. Cynoscion regalis. Autocorrelation of depth-averaged larval abundance. Dashed lines are Bartlett's standard error. (A) 1988. Series length is $46 \mathrm{~h}$ (longest subset of gapped time series) with a maximum lag of $20 \mathrm{~h}$. (B) 1989 . Series length is $150 \mathrm{~h}$ with a maximum lag of $20 \mathrm{~h}$
Cross-correlation of irradiance and larval abundance in 1989 showed a significant correlation at lags of $24 \mathrm{~h}$ (Fig. 9). Correlation was negative at zero lag, and irradiance maxima led larval abundance minima by $1 \mathrm{~h}$. The power spectrum of irradiance revealed a broad band around 1 CPD (reflecting the diel light cycle), while further analysis showed no significant coherence between irradiance and larval abundance (not shown).

\section{DISCUSSION}

\section{Abundance}

In 1988 we sampled during the second seasonal peak in spawning, and mean abundance was nearly 90 ind. per $100 \mathrm{~m}^{3}$. This is similar to the highest values reported from earlier investigations in Delaware and Chesapeake Bays
In 1988 there was a tidal periodicity in depth-averaged abundance of both early-stage and late-stage larvae, and velocity again led postlarval abundance by $1 \mathrm{~h}$ (Fig. 5). However, the abundance of yolksac larvae was not significantly correlated with velocity.

The power spectrum of longitudinal velocity in 1989 reveals that the energy is concentrated in a broad band around 2 cycles per day (CPD); this band is centered on the $\mathrm{M}_{2}$ (semi-diurnal) tidal frequency of $1.93 \mathrm{CPD}$ (Fig. 6). At 4 CPD the energy had fallen off, reflecting the lack of strong tidal flow at higher frequencies. Not surprisingly, power spectra of sea level height and salinity (not shown) were similar to that for velocity. The power spectrum of depth-averaged, larval abundance also exhibited a broad peak centered at 2 CPD, but at higher frequencies the energy did not fall off as sharply, indicating substantial, high-frequency variability in larval abundance (Fig. 6).

The coherence between velocity and depth-averaged larval abundance is significant between 0 and 4 CPD (Fig. 6). The phase spectrum shows that velocity leads larval abundance by about $30^{\circ}$, i.e. by approximately 1 h at 2 CPD (Fig. 6). Between 0 and 3 CPD, there was significant coherence between larval abundance at the surface and at mid-depth, and the series were in phase (Fig. 7). There was no coherence between abundances at mid-depth and bottom, or between surface and bottom larval abundances. Coherence between depth-averaged abundance and either sea level height or salinity was weaker, but also significant near 2 CPD. However, the phase spectra showed that larval abundance leads sea level height by about 1 h and salinity by 2 h at 2 CPD (Fig. 8).

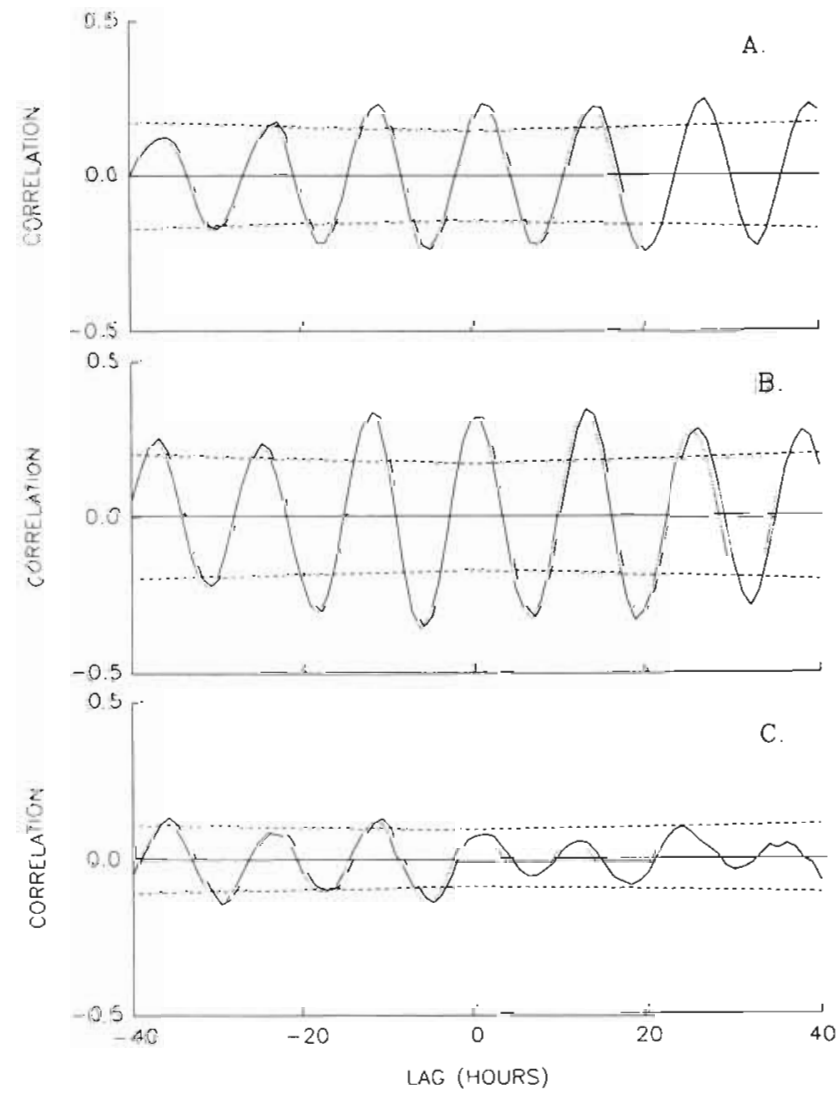

Fig. 4. Cynoscion regalis. Cross-correlation between the longitudinal component of velocity and larval abundance at each sampling depth in 1989. Dashed lines are Bartlett's standard error. Series length is $141 \mathrm{~h}$ with a maximum lag of 40 h. (A) Surface. (B) Mid-depth. (C) Bottom 


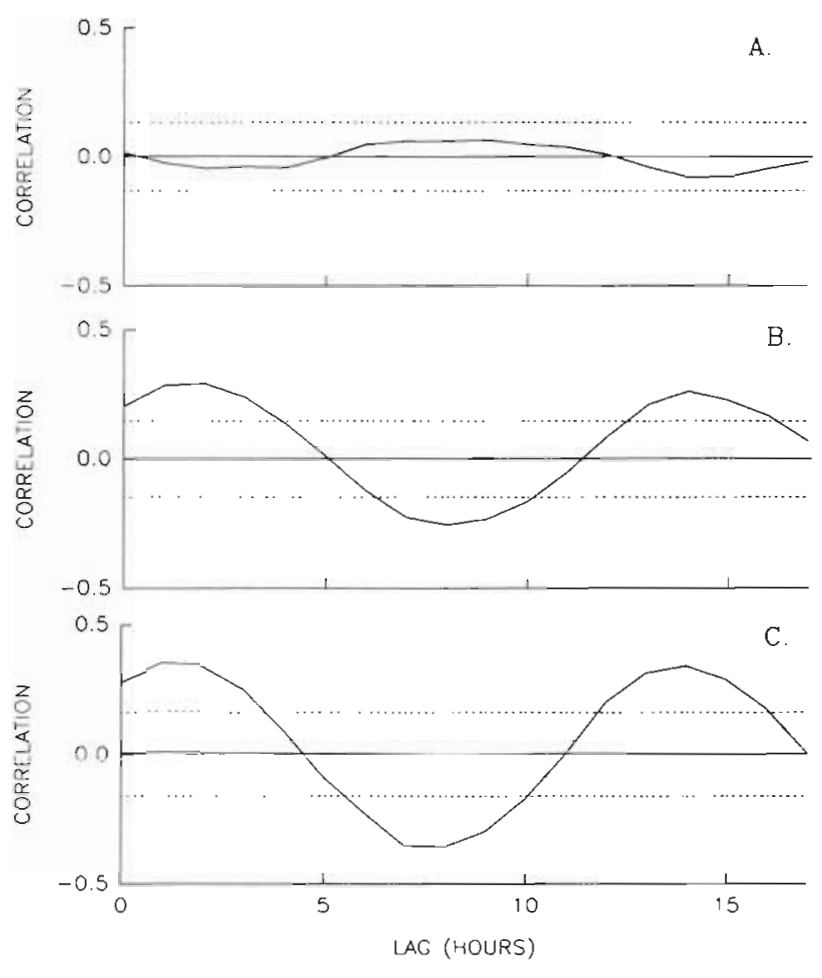

Fig. 5. Cynoscion regalis. Cross-correlation between the longitudinal component of velocity and depth-averaged, larval abundance in each size class for 1988. Dashed lines are Bartlett's standard error. Tidal series length and larval series length are $131 \mathrm{~h}$ and $114 \mathrm{~h}$ respectively. Maximum lag is $17 \mathrm{~h}$. (A) Yolksac larvae. (B) Early-stage larvae. (C) Late-stage larvae

(Olney 1983, Goshom \& Epifanio 1991), but is more than 2 orders of magnitude greater than abundance in 1989. The 1988 samples contained relatively large numbers of all larval stages, reflecting the more protracted spawning that generally occurs during the second peak (Goshorn \& Epifanio 1991). In contrast, the catch in 1989 consisted almost entirely of post-yolksac larvae, indicating that spawning had occurred a week or more before the sampling period. From these results, it is not clear whether the late-stage larvae collected in 1989 were the remnants of a large spawning episode that had since been cropped by predators or whether the main part of the early-season peak had yet to occur. In any event, the abundance of ctenophores was high in 1989, and gelatinous zooplankters have been identified as important predators of fish eggs and larvae (de Lafontaine \& Leggett 1988, Fancett \& Jenkins 1988).

\section{Selective tidal stream transport}

Several lines of evidence support the hypothesis that weakfish utilize STST for retention in Delaware Bay. Results of the Mann-Whitney U-tests show that the
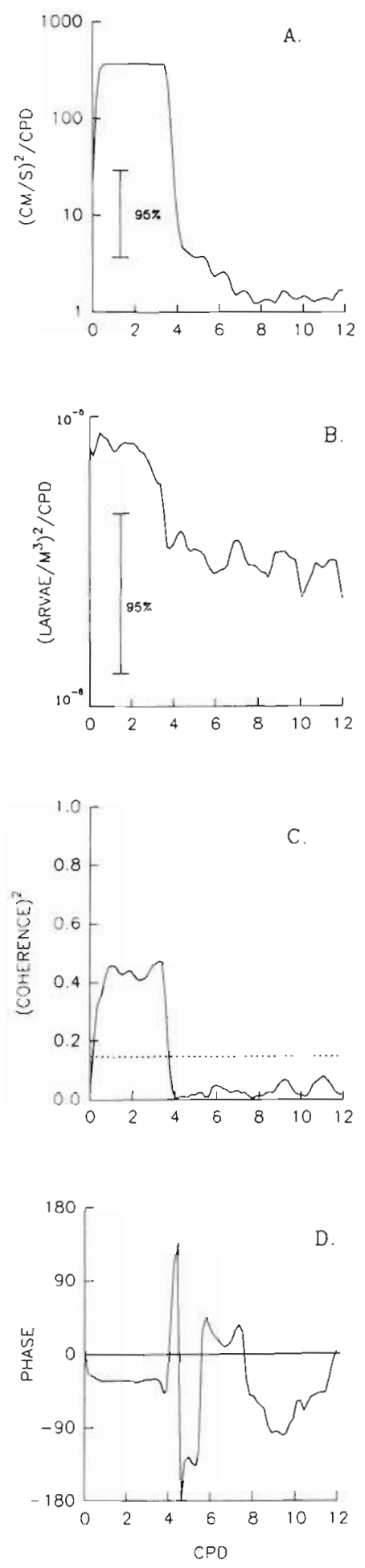

Fig. 6. Cynoscion regalis. Spectral analysis of the relationship between tidal velocity and depth-averaged, larval abundance in 1989. Series length is $141 \mathrm{~h}$. (A) Power spectrum of velocity. (B) Power spectrum of larval abundance. The $95 \%$ confidence interval about a point is represented by the vertical bar. (C) Coherence. Dashed line is the $95 \%$ significance level. (D) Phase comparison. Frequency is given as cycles per day (CPD) 

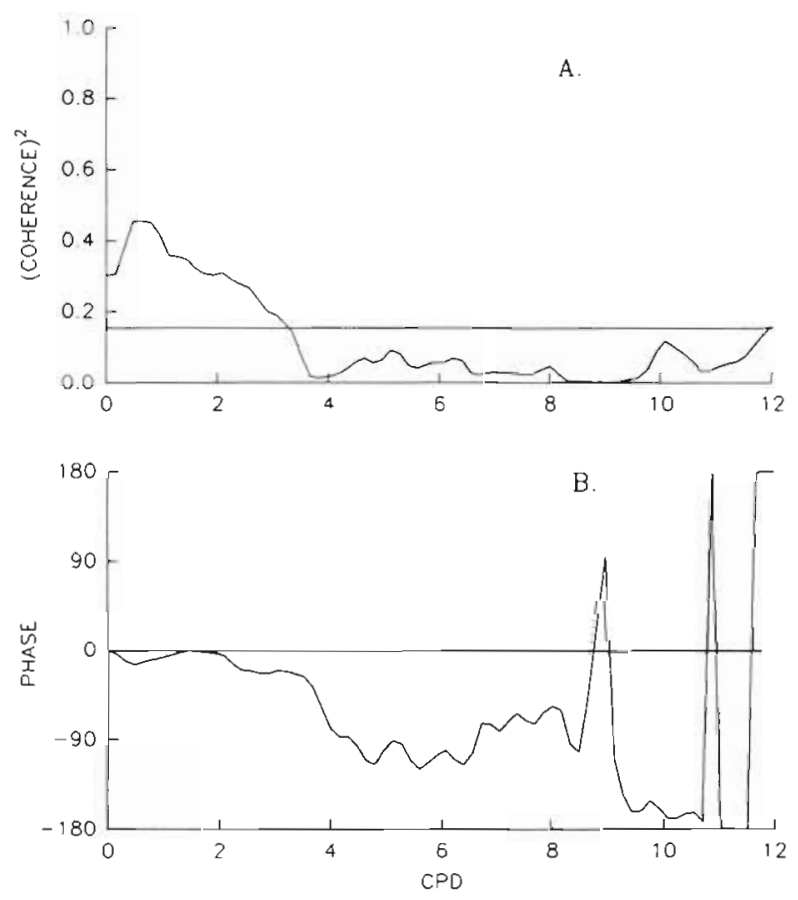

Fig. 7. Cynoscion regalis. Comparison of larval abundance at mid-depth and surface in 1989. (A) Coherence. (B) Phase. Series length is $150 \mathrm{~h}$. Frequency is given as cycles per day

(CPD). The dashed line is the $95 \%$ significance level
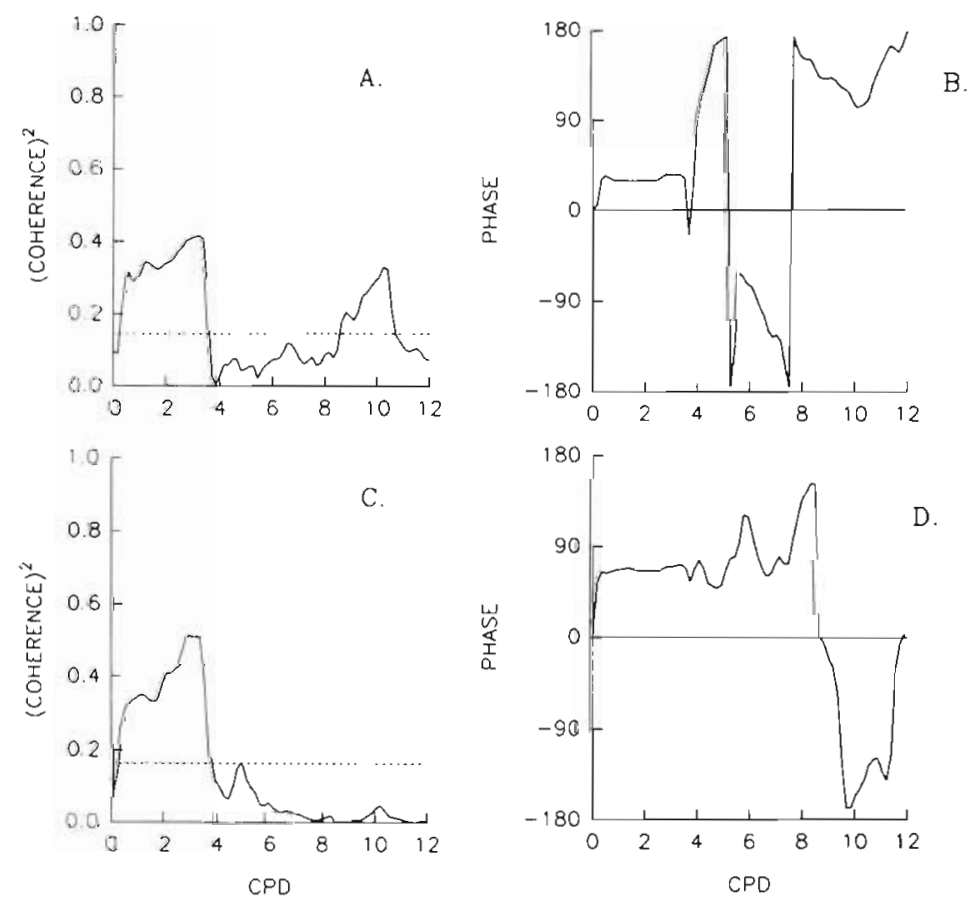

Fig. 8. Cynoscion regalis. Spectral analysis of the relationship between depth-averaged, larval abundance and sea level height or salinity in 1989. (A) Coherence with sea level height. (B) Phase with sea level height. (C) Coherence with salinity. (D) Phase with salinity. Series length is $150 \mathrm{~h}$ for sea level height and $141 \mathrm{~h}$ for salinity. Frequency is given as cycles per day (CPD). The dashed line is the $95 \%$ significance level

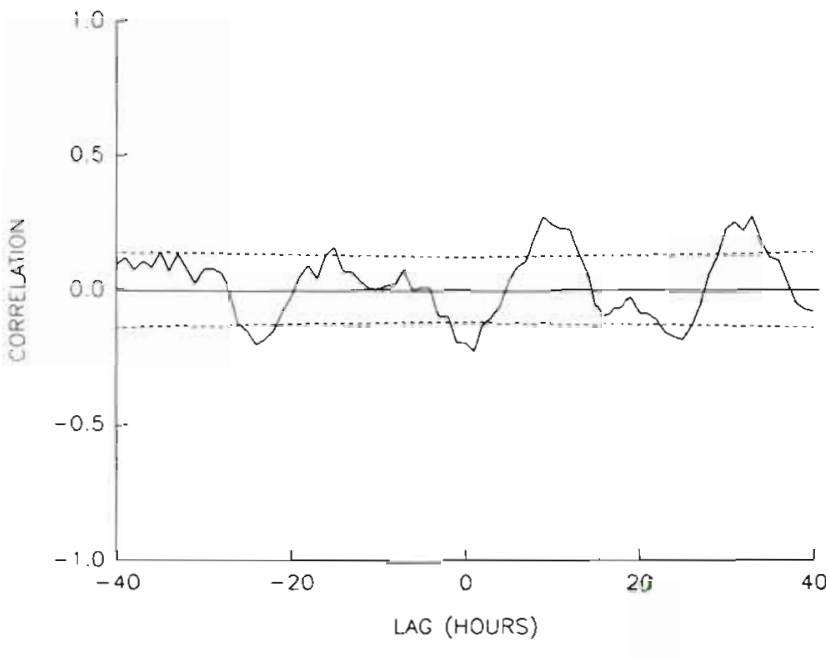

Fig. 9. Cynoscion regalis. Cross-correlation between surface irradiance and depth-averaged, larval weakfish abundance for 1989. Dashed lines are Bartlett's standard error. Series length is $150 \mathrm{~h}$ with a maximum lag of $40 \mathrm{~h}$

abundance of both early- and late-stage larvae was significantly greater at mid-depth and surface during flooding tidal phases. We interpret this as evidence of tidally rhythmic vertical migration by the larvae. In contrast, the abundance of yolksac larvae did not differ between flood and ebb tides at any depth, which suggests an ontogenetic threshold for the development of the migratory behavior. Results of cross-correlation analysis also showed an ontogenetic threshold, as the abundance of yolksac larvae was not correlated with tidal velacity, while both earlystage and late-stage larvae were correlated with velocity at lags of 1 full tidal period. Similar ontogenetic changes have been seen in the response of herring larvae to vertically migrating prey organisms (Fortier \& Leggett 1983, 1984)

Spectral analysis of the time series for larval abundance in 1989 (= post-yolksac larvae) shows enhanced energy (= variation) at a frequency of approximately $2 \mathrm{CPD}$, which also implies that weakfish larvae undergo vertical migration in phase with the tides. But if larvae were, in fact, undertaking the requisite vertical migrations in the water column, autocorrelations should become negative at lags of 0.5 tidal period $(\approx 6 \mathrm{~h})$ and then positive again at lags of 1 full tidal period $(\approx 12 \mathrm{~h}$ ). This pattern of autocorrelation has been reported for larvae of several species in the St. Lawrence Estuary (Fortier \& Leggett 1983, Laprise \& Dodson 1989, 1990), but we did not see it for weakfish larvae in 
Delaware Bay. This may have been the result of the patchy, horizontal distribution of larvae in the Bay (Goshorn 1990, Goshorn \& Epifanio 1991). In the present investigation, autocorrelation became insignificant between 2 and $3 \mathrm{~h}$ lag and remained low for additional lags. Given a decorrelation time of $2 \mathrm{~h}$ and an average tidal velocity of $40 \mathrm{~cm} \mathrm{~s}^{-1}$, the estimated larval patch size (diameter) is about $3 \mathrm{~km}$. This value is less than the $10 \mathrm{~km}$ tidal displacement typical of Delaware Bay (Garvine et al. 1992). Thus, it is unlikely that the same patches were sampled on the flood and ebb tides, and these different patches may have masked the expected tidal periodicity in the autocorrelations resulting from tidal vertical migration. Furthermore, this patchiness eliminates the possibility of a false tidal signal resulting from a large horizontal gradient in abundance as demonstrated for copepods in the St. Lawrence Estuary (Gagnon \& Lacroix 1981).

The environmental cues for the vertical migiations inherent in STST are not well understood (e.g. Boehlert \& Mundy 1988). Results of the crosscorrelation and spectral analysis on larval weakfish may shed some light on this problem. For example, cross-correlation revealed that larval abundance led both tidal height (and therefore hydrostatic pressure) and salinity by 1 to $2 \mathrm{~h}$, i.e. increases in larval abundance occurred before increases in pressure or salinity. In addition, results of spectral analysis showed that, while coherence between abundance and velocity, salinity, or sea level height was strongest at the semidiurnal frequency, tidal velocity led larval abundance by about $1 \mathrm{~h}$, while tidal height and salinity lagged larval abundance by about 1 and $2 \mathrm{~h}$ respectively. Thus, absolute pressure and salinity changes do not appear to be cues for vertical migration by weakfish larvae. In contrast, changes in velocity occur before changes in larval abundance. Thus, weakfish larvae may be responding to tidal velocity or some property of the velocity field such as vertical shear or mixing.

\section{Effects of light}

The importance of light in vertical migration of weakfish larvae is not clear. Burger (1992) showed that weakfish larvae move down in the water column in response to high irradiance and move up at low irradiance or in darkness. While this suggests a diel pattern of vertical migration, a related mathematical model showed that diel migration would generally result in transport out of the estuary during the weakfish spawning season (Burger 1992). In the present study, cross-correlation of irradiance and larval abundance was negative at zero lag and returned to significant negative correlations at lags of $24 \mathrm{~h}$. Although there was no coherence between surface irradiance and larval abundance, the coherence between larval abundance at surface and mid-depth was significant at $1 \mathrm{CPD}$ and the series were in phase. All this suggests that weakfish larvae may exhibit diel migration in Delaware Bay, as predicted by Burger's laboratory study. However, this response is weak and is superimposed on a much stronger migration at tidal frequencies.

\section{CONCLUSIONS}

The vertical distribution of other estuarine-spawned sciaenids has not been studied, but there have been some investigations of species that spawn on the continental shelf. The larvae of these species are transported across the shelf (by processes that are not well understoodi) and eventually enter the estuary as they near metamorphosis. For example, larvae of Norfolk spot Leiostomus xanthurus and Atlantic croaker Micropogonias undulatus are well mixed vertically offshore. Once in the estuary, they remdin deep in the water column, but flood abundances are greater than ebb abundances, suggesting tidally timed behavior (Weinstein et al. 1980, Miller 1988). Red drum larvae Sciaenops ocellatus show a similar pattern of behavior at Aransas Pass in Texas, again suggesting tidally rhythmic behavior (Holt et al. 1989).

Overall, our investigation corroborates results of earlier, less quantitative studies showing a deep distribution of weakfish larvae in Delaware Bay (e.g. Harmic 1958, Goshorn 1990). Thus it is reasonable to ask why larvae migrate at all, since subtidal bottom currents are generally landward in a well-mixed estuary and should act to retain larvae in the estuarine nursery. However, landward bottom flow does not occur on all time scales (Wong \& Garvine 1984, Garvine 1991), and our own observations show that subtidal flow is quite variable on a scale of days to weeks. During the 1988 sampling period the mean, subtidal current was landward at both current meter depths, while in 1989 the mean, subtidal current was seaward at both current meters. Thus over short time scales, e.g. $6 \mathrm{~d}$ in this study, the mean, subtidal circulation is variable. It is variation on just this time scale that is most important to the transport of species that have short larval duration. In 1988 all larvae would have been transported landward during the entire $6 \mathrm{~d}$ of the study, regardless of their position in the water column, while in 1989, all those larvae at or above the lower current meter would have been transported seaward with potential loss to the estuary. In contrast, larvae undergoing STST face virtually no risk of transport out of the estuary, and larvae migrating from bottom to 
surface each tidal cycle would actually be transported from the spawning grounds to upstream, juvenile nursery areas in less than $10 \mathrm{~d}$ (Burger 1992). But modelling studies have shown that extensive vertical movement is not necessary, and even larvae migrating on the order of $1 \mathrm{~m}$ during each tidal cycle would be retained in the nursery regardless of variations in mean, subtidal flow (Hill 1991a, b, Burger 1992).

Acknowledgements. We thank Mike Clancy, Joe Cope, Big John Ellsworth, Dave Goshorn and the crew of the RV 'Skimmer' for assistance with the field work, while Nita Gary and Vikki Connaughton assisted with preparation of the manuscript. We also thank Dr Richard Garvine and Dr KuoChuin Wong for help with the cross-correlations and spectral analyses. The study was supported by funds provided by the Wallop-Breaux Sport Fish Restoration Act. Funds were administered by the Delaware Department of Natural Resources and Environmental Control.

\section{LITERATURE CITED}

Boehlert, G. W., Mundy, B. C. (1988). Roles of behavioral and physical factors in larval and juvenile fish recruitment to estuarine nursery areas. Amer. Fish. Soc. Symp. 3: 51-67

Burger, M. J. (1992). The role of light, gravity and hydrostatic pressure in controlling the vertical movements of larval weakfish (Cynoscion regalis). M.Sc. thesis, University of Delaware, Newark

de Lafontaine, Y., Leggett, W. C. (1988). Predation by jellyfish on larval fish: an experimental evaluation employing in situ enclosures. Can. J. Fish. Aquat. Sci. 445: 1173-1190

Ditty, J. G. (1989). Separating early larvae of sciaenids from western North Atlantic: a review and comparison of larvae off Louisiana and Atlantic coast of the U.S. Bull. mar. Sci. 44(3): $1083-1105$

Duffy, J. T., Epifanio, C. E. (1993). Effects of larval density on the growth and survival of weakfish Cynoscion regalis in large-volume enclosures. Mar. Ecol. Prog. Ser. 104: $227-233$

Epifanio, C. E. (1988). Transport of invertebrate larvae between estuaries and the continental shelf. Am. Fish. Soc. Symp. 3: 104-114

Epifanio, C. E., Masse, A. K., Garvine, R. W. (1989). Transport of blue crab larvae by surface currents off Delaware Bay, USA. Mar. Ecol. Prog. Ser. 54: 35-41

Fancett, M. S., Jenkins, G. P. (1988). Predatory impact of scyphomedusae on ichthyoplankton and other zooplankton in Port Phillip Bay. J. exp. mar Biol. Ecol. 116: $63-77$

Fortier, L., Leggett, W. C. (1983). Vertical migrations and transport of larval fish in a partially mixed estuary. Can J. Fish. Aquat. Sci. 40; 1543-1555

Fortier, L., Leggett, W. C. (1984). Small-scale covariability in the abundance of fish larvae and their prey. Can. J. Fish Aquat. Sci. 41: 502-512

Forward, R. B. Jr (1989). Behavioral responses of crustacean larvae to rates of salinity change. Biol. Bull. 176: 229-238

Forward, R. B. Jr (1990). Responses of crustacean larvae to hydrostatic pressure: behavioral basis of high barokenesis. Mar. Behav. Physiol. 17: 223-232

Gagnon, M., Lacroix, G. (1981). Zooplankton sample variability in a tidal estuary: an interpretative model. Limnol. Oceanogr. 26(3): 401-413
Garvine, R. W. (1991). Subtidal frequency estuary-shelf interaction: observations near Delaware Bay. J. geophys. Res. 96: 7049-7064

Garvine, R. W., McCarthy, R. K., Wong, K.-C. (1992). The axial salinity distribution in the Delaware Estuary and its weak response to river discharge. Estuar, coast. Shelf Sci 35: $157-165$

Goshorn, D. M. (1990). Distribution of larval weakfish (Cynoscion regalis) in Delaware Bay and the relationship of field prey concentration to laboratory determined growth and mortality rates. Ph.D. thesis, University of Delaware, Newark

Goshorn, D. M., Epifanio, C. E. (1991). Diet of larval weakfish and prey abundance in Delaware Bay. Trans. Am. Fish. Soc. 120: $684-692$

Harmic, J L. (1958). Some aspects of the development and ecology of the pelagic phase of the gray squeteague, Cynoscion regalis (Bloch \& Schneider), in the Delaware estuary. Ph.D. thesis, University of Delaware, Newark

Hill, A. E. (1991a). Vertical migration in tidal currents. Mar Ecol. Prog. Ser. 75: 39-54

Hill, A. E. (1991b). A mechanism for horizontal zooplankton transport by vertical migration in tidal currents. Mar. Biol. 111: $485-492$

Holt, S. A., Holt, G. J., Arnold, C. R. (1989). Tidal stream transport of larval fishes into non-stratified estuaries. Rapp. P.-v. Réun. Cons. int. Explor. Mer 191: 100-104

Laprise, R., Dodson, J. J. (1989). Ontogeny and importance of tidal vertical migrations in the retention of larval smelt Osmerus mordax in a well-mixed estuary. Mar. Ecol. Prog Ser. 55: 101-111

Laprise, R., Dodson, J. J. (1990). The mechanism of retention of pelagic tomcod, Microgadus tomcod, larvae and juveniles in the well-mixed part of the St. Lawrence Estuary. Environ. Biol. Fish. 29: 293-302

Lippson, A. J., Moran, R. L. (1974). Manual for identification of early developmental stages of fishes of the Potomac River estuary. Environmental Technology Center, Martin Marietta Corporation, Baltimore

McCleave, J. D., Kleckner, R. C. (1982). Selective tidal stream transport in the estuarine migration of glass eels of the American eel (Anguilla rostrata). J. Cons. int. Explor. Mer 40: $262-271$

Mercer, L. P. (1983). A biological and fisheries profile of weakfish. Cynoscion regalis. North Carolina Dept of Natural Resources and Community Development, Division of Marine Fisheries, Special Scientific Report No. 39

Miller, J. M. (1988). Physical processes and the mechanisms of coastal migrations of immature marine fishes. Am. Fish. Soc. Symp. 3: 68-76

Nelson, W. R., Ingham, M. C., Schaaf, W. E. (1977). Larval transport and year-class strength of Atlantic menhaden, Brevoortia tyrannus. Fish. Bull. U.S. 75(1): 23-41

Olney, J. E. (1983). Eggs and early larvae of the bay anchovy, Anchoa mitchilli, and the weakfish, Cynoscion regalis, in lower Chesapeake Bay with notes on associated ichthyoplankton. Estuaries 6(1): 20-35

Wang, J. C. S., Kernehan, R. G. (1979). Fishes of the Delaware Estuary: a guide to the early life histories. E. A. Communications, Towson, MD

Wong, K.-C., Garvine, R. W. (1984). Observations of windinduced, subtidal variability in the Delaware Estuary. J. geophys. Res. 89: 10589-10597

Weinstein, M. P., Weiss, S. L., Hodson, R. G., Gerry, L. R. (1980). Retention of three taxa of postlarval fishes in an intensively flushed tidal estuary, Cape Fear River. Fish. Bull. U.S. 78: 419-436 
Yoder, J. A. (1983). Statistical analysis of the distribution of fish eggs and larvae on the southeastern U.S. continental shelf with comments on oceanographic processes that may

This article was submitted to the editor affect larval survival. Estuar., coast. Shelf Sci. 17: 637-650 Zar, J. H. (1984). Biostatistical analysis, 2nd edn. Prentice Hall, Inc., Englewood Cliffs, NJ

Manuscript first received: April 19, 1993

Revised version accepted: March 22, 1994 